\title{
Como está o seu ciclo menstrual? Uma Avaliação de Comunicabilidade e Percurso Cognitivo do Aplicativo Clue
}

\author{
Laura Engelmann \\ PUCRS, Escola Politécnica \\ Porto Alegre, Brasil \\ laura.engelmann@acad.pucrs.br
}

\author{
Ingrid Signoretti \\ PUCRS, Escola Politécnica \\ Porto Alegre, Brasil \\ ingrid.manfrim@acad.pucrs.br
}

\author{
Matheus Prestes \\ PUCRS, Escola Politécnica \\ Porto Alegre, Brasil \\ matheus.plautz@acad.pucrs.br
}

\author{
Vivian Larréa \\ PUCRS, Escola Politécnica \\ Porto Alegre, Brasil \\ vivian.silveira@acad.pucrs.br
}

\author{
Milene Silveira \\ PUCRS, Escola Politécnica \\ Porto Alegre, Brasil \\ milene.silveira@pucrs.br
}

\section{RESUMO}

O controle de ciclo menstrual é uma das maiores dores de cabeça das mulheres. Saber quando foi a última menstruação, quando iniciou a cartela do anticoncepcional e quando é a janela de fertilidade são algumas das muitas preocupações do público feminino. Hoje, a abrangência do uso de smartphones e a quantidade de aplicativos que ajudam a gerenciar atividades diárias, trouxe consigo uma solução para os anseios das mulheres. Neste contexto, foi realizada a avaliação do aplicativo Clue, a fim de entender como ele auxilia no acompanhamento do ciclo menstrual. Para isto, foram utilizados dois métodos de avaliação: como método de inspeção foi utilizado o Percurso Cognitivo e como método de observação de uso foi utilizada a Avaliação de Comunicabilidade. Foi possível verificar que o aplicativo possui alguns problemas relacionados com a comunicação, mas que, de maneira geral, os usuários se mostraram satisfeitos com seu uso.

\section{Palavras-chave}

Clue, Percurso Cognitivo, Avaliação de Comunicabilidade.

\section{INTRODUÇÃO}

A popularização dos smartphones tem sido considerada por muitos a revolução tecnológica de maior impacto nos últimos tempos [1]. Hoje, smartphones são veículos de fácil acesso à internet e oferecem dos mais variados tipos de aplicativos [3]. As principais características que os dispositivos móveis trouxeram consigo são a mobilidade, a portabilidade e a flexibilidade [1]. Junto dessas características, os smartphones oferecem várias utilidades a

Permission to make digital or hard copies of all or part of this work for personal or classroom use is granted without fee provided that copies are not made or distributed for profit or commercial advantage and that copies bear this notice and the full citation on the first page. Copyrights for components of this work owned by others than the author(s) must be honored. Abstracting with credit is permitted. To copy otherwise, or republish, to post on servers or to redistribute to lists, requires prior specific permission and/or a fee. Copyright 2018 SBC.

IHC 2018, Anais Estendidos do XVII Simpósio Brasileiro sobre Fatores Humanos em Sistemas Computacionais Outubro 22-26, 2018, Belém, Brasil

Competição de Avaliação - Pós-graduação seus usuários, dentre elas, o auxílio em atividades diárias, lazer, entretenimento e monitoramento da saúde, além de poder ser usado como um canal de divulgação de produtos e/ou serviços [8].

Neste contexto surgem os aplicativos que tem como público-alvo as mulheres e, dentre eles, alguns exemplos são: Maya ${ }^{1}$, My Pill $^{2}$, Meu Calendário ${ }^{3}$ e o Clue ${ }^{4}$. Todos estes aplicativos têm como objetivo comum auxiliar no cuidado da saúde feminina. Como foco de estudo deste trabalho, o aplicativo Clue foi escolhido por estar entre os 10 aplicativos mais bem avaliados na categoria Saúde e Fitness nas principais lojas de aplicativos hoje utilizadas, a Play Store e a Apple Store. Além disso, o Clue já era de conhecimento dos autores deste trabalho.

O Clue auxilia o público feminino com questões íntimas do seu próprio corpo, como, por exemplo, acompanhamento de ciclo menstrual, janela de fertilidade, tensão pré-menstrual (TPM), menopausa, sentimentos, gravidez e monitoramentos gerais. Ele está disponível para pessoas que tenham um smartphone tanto na plataforma iOS quanto Android.

Inicialmente, apesar da experiência dos avaliadores no uso do aplicativo escolhido, foi realizado um breve estudo sobre todas as funcionalidades existentes no mesmo. Após, a fim de avaliar o fator de usabilidade referente a facilidade de aprendizagem e, também, se existem rupturas de comunicação que possam impactar a interação, dois métodos foram aplicados: um método de avaliação por inspeção (Percurso Cognitivo) e um método de avaliação por observação de uso (Avaliação de Comunicabilidade). Ambos os métodos foram aplicados para que fosse possível

\footnotetext{
${ }^{1}$ http://maya.live/eng.html

${ }^{2}$ http://mypill.app

${ }^{3}$ ttps://play.google.com/store/apps/details?id=com.populara pp.periodcalendar\&hl=pt_BR

${ }^{4}$ http://helloclue.com
} 
traçar um comparativo entre os resultados obtidos e assim obter um melhor entendimento dos problemas encontrados.

O artigo está estruturado da seguinte forma: na próxima seção é descrita a metodologia utilizada e sua justificativa. Na sequência, os métodos aplicados (Percurso Cognitivo e Avaliação de Comunicabilidade) são descritos de forma detalhada. Nas seções posteriores são apresentadas a discussão do trabalho e as considerações finais.

\section{METODOLOGIA}

Segundo Barbosa e Silva [2], existem diversos métodos que podem ser aplicados para avaliar a qualidade de uso de um sistema, sendo que cada um deles atende melhor a certos objetivos de avaliação que se deseja alcançar. Para cada método existente, é orientado quando e onde os dados devem ser coletados, como esses dados devem ser analisados e quais os critérios de qualidade de uso são propostos em seus escopos, podendo ser focados na acessibilidade, comunicabilidade, usabilidade ou experiência de uso. Quanto à classificação, os métodos de avaliação de Interação Humano-Computador (IHC) podem ser divididos em três categorias: Métodos de Investigação, de Observação de Uso e de Inspeção [2].

De acordo com o objetivo deste trabalho, que é entender como o aplicativo Clue auxilia no acompanhamento do ciclo menstrual das mulheres, procurou-se avaliar o fator de usabilidade referente à facilidade de aprendizagem sobre o aplicativo escolhido, e, para isso, utilizou-se o método de Percurso Cognitivo (MPC) [2]. Também procurou-se encontrar as possíveis rupturas de comunicação que o aplicativo poderia possuir, com aplicação do método de Avaliação de Comunicabilidade (MAC) [4].

Cada método escolhido possui um foco diferente. O MPC foi utilizado para prever o comportamento do usuário e as dificuldades que este potencialmente encontrará devido a problemas de design, enquanto o MAC foi aplicado para analisar a comunicação designer-usuário e ver se, caso rupturas de comunicação fossem encontradas, estas confirmariam ou não os achados pela aplicação do MPC.

Segundo Barbosa e Silva [2] como em um método de inspeção o envolvimento direto dos usuários não existe, podem não ser encontrados problemas que os usuários teriam ou também podem ser encontrados pontos problemáticos que os usuários não teriam dificuldades, assim resolvemos aplicar o MPC e o MAC para uma avaliação mais aprofundada do aplicativo e para que uma possível complementação de resultados fosse realizada.

Nas próximas seções são descritas de forma detalhada a realização do MPC e do MAC. Para fins de comparação, as tarefas definidas para o MPC são as mesmas utilizadas no MAC.

\section{APLICAÇÃO DO PERCURSO COGNITIVO}

Segundo Barbosa e Silva [2], o MPC é um método de inspeção que busca tratar de experiências de uso potenciais e não reais, pois normalmente não envolvem diretamente os usuários no experimento. Sendo assim, com o uso do MPC, procura-se descobrir se o aplicativo possui uma interface coerente e clara para a utilização dos usuários, atendendo a característica de um software fácil sobre o critério de aprendizagem através da exploração de sua interface. Com o MPC, os próprios avaliadores colocam-se no lugar dos usuários e percorrem a interface inspecionando as ações projetadas para os usuários [5]. De acordo com Barbosa e Silva [2], os seguintes passos fazem parte do Percurso Cognitivo:

- Definição do perfil de usuários e das tarefas a serem executadas com foco no objetivo a ser atingido pela avaliação, assim como as ações necessárias para a realização de cada tarefa.

- Realização da análise pelos avaliadores: os avaliadores executam os passos necessários para cada uma das tarefas estabelecidas anteriormente.

- Consolidação dos resultados obtidos a partir da análise feita pelos avaliadores.

- Construção de relatório com dos resultados com os problemas encontrados.

O intuito desta inspeção é, a partir das tarefas definidas, os avaliadores serem capazes de responder as seguintes questões [2]:

- O usuário vai tentar atingir o efeito correto?

- O usuário vai notar que a ação correta está disponível?

- O usuário vai associar a ação correta com o efeito que está tentando atingir?

- Se a ação for executada corretamente, o usuário vai perceber que está progredindo na direção de concluir a tarefa?

Os avaliadores que aplicaram o MPC foram quatro estudantes de pós-graduação, com conhecimentos iniciais sobre a área, sendo esta a primeira aplicação do método. É importante destacar que o MPC pode ser aplicado por apenas um avaliador, mas, como estratégia, neste estudo, os quatro estudantes participaram da aplicação do MPC. O intuito era identificar o grau de dificuldade das tarefas definidas e quais seriam as possíveis dificuldades que os usuários iriam enfrentar.

Além de descreverem os problemas que acreditavam que os usuários teriam ao realizar as tarefas, a cada avaliador foram entregues as quatro perguntas (citadas anteriormente) e para cada uma delas, eles deveriam responder " $S$ " para sim e "N" para não.

A seguir serão detalhadas as etapas seguidas bem como os resultados obtidos.

\section{Preparação (Identificação do Perfil do Usuário)}

Devido ao aplicativo escolhido para este estudo ter como foco principal o público feminino (há casos em que o parceiro também pode ser usuário da ferramenta), foi 
possível traçar o perfil desejado de forma fácil, considerando que neste trabalho o foco era o público principal, as mulheres. Sem mais restrições, o perfil dos usuários são mulheres com o ciclo menstrual ativo e que já possuem experiência de uso com smartphones, dado que não saber usar este tipo de dispositivo traria uma dificuldade a mais que poderia impactar no uso do aplicativo em si.

\section{Detalhamento das Tarefas}

Para a aplicação do MPC, três tarefas foram criadas e os avaliadores deste estudo percorreram as sequências de ações de cada tarefa, colocando-se no contexto de um cenário típico de uso do aplicativo, para que fosse possível responder as questões propostas pelo método.

A Tabela 1 mostra os passos detalhados e necessários para a realização de cada uma das tarefas estabelecidas.

A Tarefa I tem como objetivo acessar o aplicativo e informar todos os dados necessários a respeito do ciclo menstrual da usuária. Esses dados são necessários para que o aplicativo forneça ao usuário informações sobre seu ciclo menstrual. Esta tarefa foi criada e estabelecida com o objetivo de verificar se o processo inicial de fornecimento de dados por parte dos usuários é realizado de forma fácil, visto que, todo e qualquer usuário que utiliza o aplicativo, deverá obrigatoriamente passar por esta etapa, ou seja, torna-se uma etapa fundamental.

As Figuras 1, 2, 3 e 4, respectivamente, referem-se a todas as telas necessárias para que o usuário consiga completar o percurso da Tarefa I.

Diferente da Tarefa I, as Tarefas II e III não são etapas obrigatórias para quem utiliza a aplicação, no entanto, não deixam de ter objetivos importantes. Na tarefa II, o objetivo é ativar ao menos três tipos de lembretes diferentes.

A Figura 5 traz todas as telas necessárias para que o usuário consiga alcançar o objetivo referente a esta segunda tarefa. Nesse caso, tanto nesta tarefa quanto na tarefa seguinte (Tarefa III), o usuário deve partir da tela (a) Configuração.

Já na Tarefa III, as opções de monitoramento devem ser encontradas e ativadas, e, caso necessário, o usuário pode cadastrar monitoramentos de seu interesse.

A Figura 6 traz as telas que são necessárias para completar o objetivo referente a Tarefa III. São apenas duas telas, a primeira (a) Configuração para chegar nas opções de monitoramento e a própria tela de (b) Opções de monitoramento para a seleção de quais opções o usuário deseja selecionar.

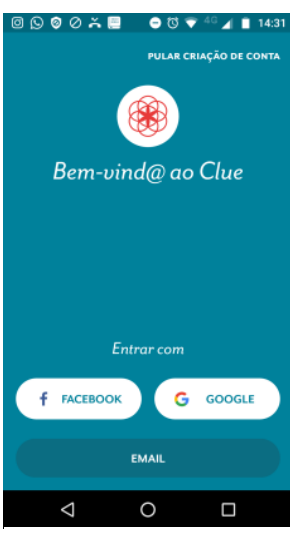

(a) Bem-vinda ao Clue

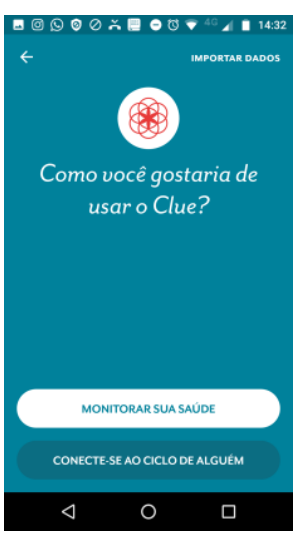

(b) Monitorar sua saúde
Figura 1. Telas iniciais referentes a Tarefa I

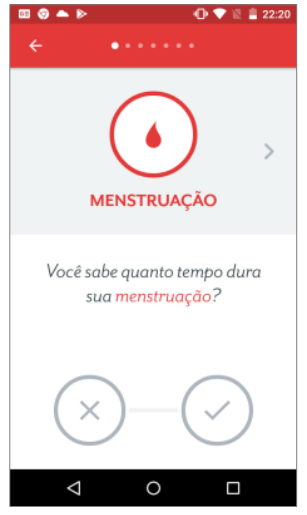

(a) Menstruação

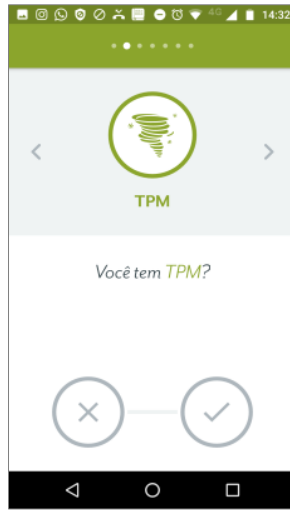

(b) TPM
Figura 2. Telas de configuração referentes a Tarefa I

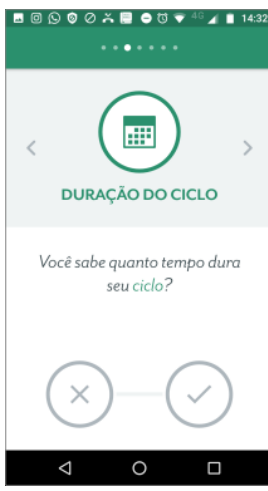

(a) Ciclo

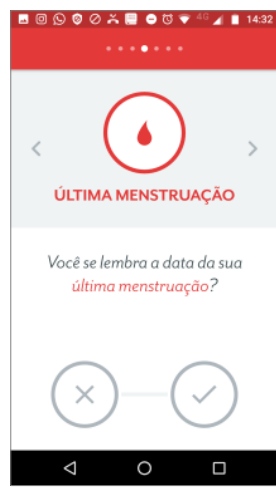

(b) Última menstruação

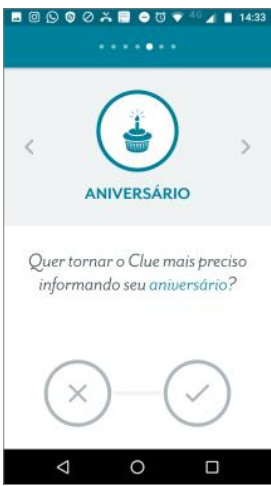

(c) Aniversário
Figura 3. Telas de configuração referentes a Tarefa I 


\begin{tabular}{c|l|l|l} 
Passos & \multicolumn{1}{|c|}{ Tarefa I } & \multicolumn{1}{|c}{ Tarefa II } & \multicolumn{1}{c}{ Tarefa III } \\
\hline $\mathbf{1 .}$ & $\begin{array}{l}\text { Acessar o aplicativo e preencher } \\
\text { os dados sem precisar criar uma } \\
\text { conta }\end{array}$ & $\begin{array}{l}\text { Clicar no ícone de } \\
\text { configurações }\end{array}$ & $\begin{array}{l}\text { Clicar no ícone de } \\
\text { configurações }\end{array}$ \\
\hline $\mathbf{2 .}$ & $\begin{array}{l}\text { Concordar com os termos de } \\
\text { serviços }\end{array}$ & Acessar a opção: Lembretes & $\begin{array}{l}\text { Acessar a opção: Opções de } \\
\text { monitoramento }\end{array}$ \\
\hline $\mathbf{3 .}$ & “Clicar” em monitorar & Selecione três lembretes & $\begin{array}{l}\text { Selecionar dois tipos de } \\
\text { monitoramento }\end{array}$ \\
\hline $\mathbf{4 .}$ & $\begin{array}{l}\text { Preencher duração da } \\
\text { menstruação }\end{array}$ & \\
\hline $\mathbf{5 .}$ & Preencher duração da TPM & & \\
\hline $\mathbf{6 .}$ & Preencher duração do ciclo & & \\
\hline $\mathbf{7 .}$ & Preencher última menstruação & & \\
\hline $\mathbf{8 .}$ & Informar aniversário & & \\
\hline $\mathbf{9 .}$ & $\begin{array}{l}\text { Informar tipo de controle de } \\
\text { natalidade }\end{array}$ & & \\
\hline $\mathbf{1 0}$ & $\begin{array}{l}\text { Informar se deseja ter lembretes } \\
\text { (caso selecione pílula como } \\
\text { controle de natalidade) }\end{array}$ & & \\
\hline
\end{tabular}

Tabela 1. Passo a passo das tarefas

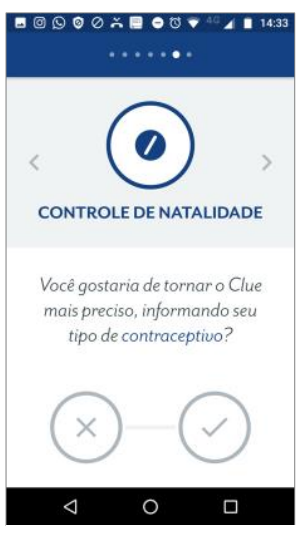

(a) Controle de natalidade

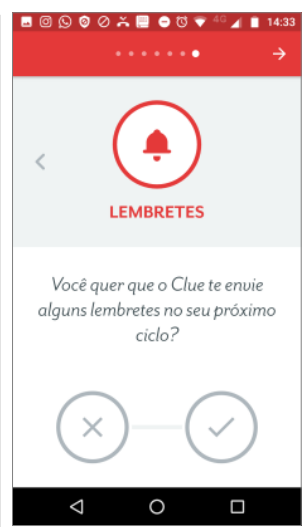

(b) Lembretes

Figura 4. Telas de configuração referentes a Tarefa I

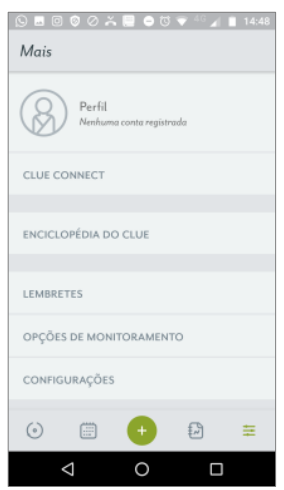

(a) Configuração

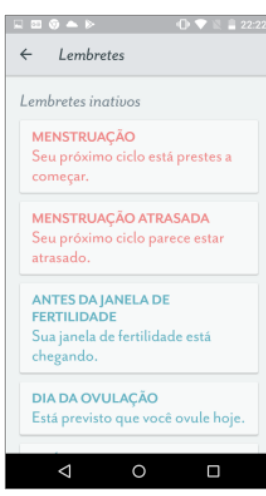

(b) Lembretes

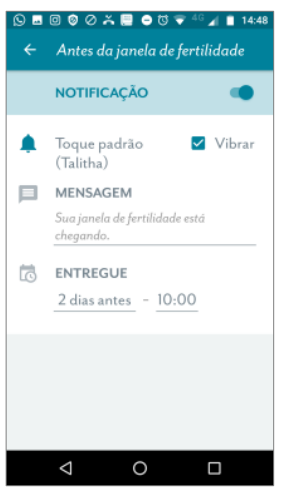

(c) Ativar lembretes

Figura 5. Telas referentes a Tarefa II

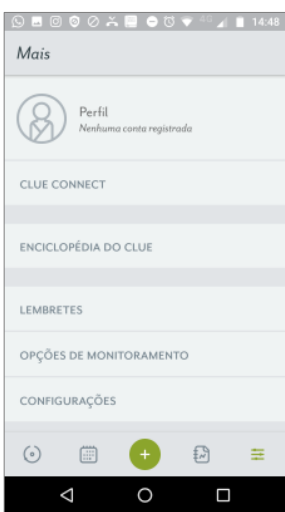

(a) Configuração

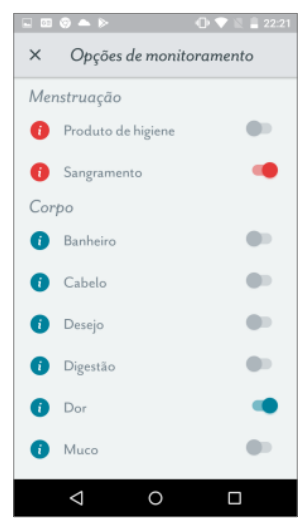

(b) Opções de monitoramento

Figura 6. Telas referentes a Tarefa III 


\section{Resultados}

Após todos os avaliadores finalizarem as tarefas, os resultados foram analisados e consolidados conforme descrição a seguir.

\section{P1. O Usuário vai Tentar Atingir o Efeito Correto?}

Para a Tarefa I, todos os avaliadores apontaram que a maior dificuldade que os usuários enfrentariam seria executar o primeiro passo desta tarefa (Tabela 1).

$\mathrm{Na}$ Tarefa II, eles indicaram que talvez o usuário ficasse um tempo navegando entre os menus até conseguir encontrar a opção "Lembretes" - passo 2 da tarefa (Tabela 1).

Como consequência disto, na Tarefa III os avaliadores disseram que, como o usuário já teria encontrado o menu "Configurações" no passo 1 da tarefa II (Tabela 1), seria muito fácil para eles acharem a opção "Opções de monitoramento" - passo 2 da Tarefa III.

A Tabela 2 mostra a resposta de todos os avaliadores para esta pergunta.

\begin{tabular}{c|c|c|c|c} 
Tarefa & $\begin{array}{c}\text { Avaliador } \\
\text { I }\end{array}$ & $\begin{array}{c}\text { Avaliador } \\
\text { II }\end{array}$ & $\begin{array}{c}\text { Avaliador } \\
\text { III }\end{array}$ & $\begin{array}{c}\text { Avaliador } \\
\text { IV }\end{array}$ \\
\hline T1 & S & S & S & S \\
\hline T2 & N & N & S & N \\
\hline T3 & S & S & S & N
\end{tabular}

Tabela 2. Respostas da pergunta 1 (P1)

P2. O Usuário Vai Notar que a Ação Correta Está Disponível?

Da mesma forma que a pergunta anterior, os avaliadores apontaram que a maior dificuldade ainda está no início da Tarefa I. Porém, depois que eles conseguem identificar esse passo (Tabela 1), os avaliadores disseram que a sequência da tarefa é muito intuitiva e o usuário consegue perceber que está executando os passos corretamente.

Quanto às Tarefas II e III, os avaliadores afirmam que o aplicativo se torna muito intuitivo e que é perceptível que os passos estão sendo executados corretamente.

A Tabela 3 mostra a resposta de todos os avaliadores para esta pergunta.

\begin{tabular}{c|c|c|c||c} 
Tarefa & $\begin{array}{c}\text { Avaliador } \\
\text { I }\end{array}$ & $\begin{array}{c}\text { Avaliador } \\
\text { II }\end{array}$ & $\begin{array}{c}\text { Avaliador } \\
\text { III }\end{array}$ & $\begin{array}{c}\text { Avaliador } \\
\text { IV }\end{array}$ \\
\hline T1 & $\mathrm{S}$ & $\mathrm{S}$ & $\mathrm{S}$ & $\mathrm{S}$ \\
\hline $\mathrm{T} 2$ & $\mathrm{~S}$ & $\mathrm{~S}$ & $\mathrm{~S}$ & $\mathrm{~S}$ \\
\hline $\mathrm{T} 3$ & $\mathrm{~S}$ & $\mathrm{~S}$ & $\mathrm{~S}$ & $\mathrm{~S}$ \\
& \multicolumn{2}{|c}{ Tabela 3. Respostas da pergunta 2 (P2) }
\end{tabular}

P3. O Usuário Vai Associar a Ação Correta Com o Efeito que Está Tentando Atingir?

Esta pergunta também gerou unanimidade para todos os avaliadores nas três tarefas. Os avaliadores acreditam que os usuários conseguirão enxergar que a ação realizada está gerando o efeito desejado. A Tabela 4 mostra a resposta de todos os avaliadores para esta pergunta.

\begin{tabular}{c|c|c|c|c} 
Tarefa & $\begin{array}{c}\text { Avaliador } \\
\text { I }\end{array}$ & $\begin{array}{c}\text { Avaliador } \\
\text { II }\end{array}$ & $\begin{array}{c}\text { Avaliador } \\
\text { III }\end{array}$ & $\begin{array}{c}\text { Avaliador } \\
\text { IV }\end{array}$ \\
\hline T1 & S & S & S & S \\
\hline T2 & S & S & S & S \\
\hline T3 & S & S & S & S
\end{tabular}

Tabela 4. Respostas da pergunta 3 (P3)

P4. Se a Ação for Executada Corretamente, o Usuário Vai Perceber que Está Progredindo na Direção de Concluir a Tarefa?

Para os avaliadores, é possível que, em alguns casos, o usuário sinta que "não existe" um fim para as tarefas. Por exemplo, o avaliador I diz que: “...ao final da primeira tarefa, é possível que o usuário se sinta perdido, pois logo após preencher o último passo da tarefa (Passo 10 - Tarefa I: Tabela 1) é exibido o círculo do ciclo menstrual e não existe nenhuma mensagem avisando ao usuário que ele preencheu as informações necessárias para iniciar a utilização do aplicativo.".

Nas demais tarefas (II e III) houve divergência entre as respostas. Os avaliadores I e II acreditam que o usuário não consiga ver o progresso da realização das tarefas para a sua conclusão.

A Tabela 5 mostra a resposta de todos os avaliadores para esta pergunta.

\begin{tabular}{c|c|c|c|c} 
Tarefa & $\begin{array}{c}\text { Avaliador } \\
\text { I }\end{array}$ & $\begin{array}{c}\text { Avaliador } \\
\text { II }\end{array}$ & $\begin{array}{c}\text { Avaliador } \\
\text { III }\end{array}$ & $\begin{array}{c}\text { Avaliador } \\
\text { IV }\end{array}$ \\
\hline T1 & N & S & S & S \\
\hline T2 & N & N & S & S \\
\hline T3 & N & N & S & S \\
\multicolumn{2}{|c}{ Tabela 5. Respostas da pergunta 4 (P4) }
\end{tabular}

APLICAÇÃO DA AVALIAÇÃO DE COMUNICABILIDADE

O MAC tem como objetivo observar os usuários durante o uso de um determinado sistema interativo, por meio de um ambiente controlado pelo avaliador, onde o mesmo analisa as tarefas do usuário realizadas sobre o sistema, capturando, através da observação, as possíveis rupturas encontradas durante a interação [4].

O MAC é composto pelos seguintes passos [2]:

- Preparação - preparar todo o material necessário para a realização do teste, criação de cenário das tarefas, elaboração dos questionários pré- e pós-teste e do Termo de Consentimento Livre e Esclarecido.

- Coleta de dados - aplicação do teste, incluindo os questionários de pré- e pós-teste.

- Etiquetagem.

- Interpretação.

- Elaboração do perfil semiótico. 
Para a realização da Avaliação de Comunicabilidade, um ambiente controlado, como um laboratório, seria o ideal para a execução do experimento [2]. Apesar de não ter sido realizado em um laboratório, a observação foi realizada em uma sala de reuniões, reservada para esta finalidade.

Os participantes selecionados foram convidados a realizar um conjunto de tarefas utilizando o aplicativo Clue, sendo as experiências de uso observadas e registradas. Os avaliadores observaram e realizaram anotações durante a interação dos participantes com o aplicativo e a captura da tela de cada um deles foi registrada em vídeo para uma análise posterior. Essa captura da tela dos participantes em vídeo foi feita por meio de um aplicativo instalado no celular chamado AZ Screen Recorder ${ }^{5}$. O aplicativo foi baixado e configurado apenas para a plataforma Android. Para a plataforma iOS não foi necessária a instalação de um aplicativo para captura, dado que, o sistema operacional já possui uma função para gravação de tela de forma nativa.

Todos os participantes receberam um smartphone já com o aplicativo instalado. Foi decidido não utilizar o smartphone de cada participante para a realização do teste pelo fato de precisarmos instalar e configurar o aplicativo para gravação das telas. Além disso, por se tratar de um smartphone cuidamos para que nada atrapalhasse o participante durante o experimento, como, por exemplo, a exibição de notificações de outros aplicativos. Cuidou-se para os participantes manterem o foco apenas na realização das tarefas.

\section{Participantes}

A todos os participantes, antes de mais nada, foi apresentado um Termo de Consentimento Livre e Esclarecido. Estando eles de acordo, um questionário para coleta de dados de perfil foi aplicado antes da interação com o sistema e, após a interação, outro questionário foi aplicado, para obter dados sobre como foi o uso do aplicativo. O perfil dos participantes definido pela equipe para a aplicação do teste eram pessoas do sexo feminino com o ciclo menstrual ativo que já possuíssem experiência de uso com smartphone. Este perfil foi definido com base no público-alvo do aplicativo Clue.

Quanto a quantidade de participantes no experimento, de acordo com de Souza [6], o estudo deve ser aplicado com no mínimo cinco e no máximo dez participantes. Neste estudo o teste foi realizado com oito participantes, que atendem ao perfil estabelecido. Após o teste com todos eles, uma análise dos vídeos da interação de cada participante foi feita, a fim de realizar a etiquetagem. Na Tabela 6 é exibido o perfil dos participantes selecionados.

\section{Cenários}

Todos os participantes receberam uma descrição inicial de um cenário principal. Este cenário foi feito para contextualizar o participante do assunto e, nele, é descrita a importância de acompanhar o ciclo menstrual. A partir dessa descrição, três tarefas (as mesmas realizadas pelos avaliadores no MPC) foram distribuídas. As tarefas foram aplicadas de forma sequente e na ordem em que estão listadas a seguir. A primeira delas tem como objetivo fazer com que o participante crie um cadastro no aplicativo e informe dados básicos sem a necessidade de criar uma conta. A segunda tem como objetivo fazer com que o participante ative lembretes do aplicativo. Por último, na tarefa três, o usuário deve selecionar opções de monitoramento.

A seguir são descritos - na sequência em que foram entregues aos usuários - os cenários, usados para apresentação das tarefas:

"Ao acessar o aplicativo você não deve criar uma conta, mas deve concordar com os termos de serviços. Alguns dados de cadastro devem ser preenchidos para iniciar o monitoramento de sua saúde. Esses dados são importantes para que o aplicativo consiga fornecer com precisão informações sobre sua saúde e seu ciclo menstrual. Você deve preencher dados de menstruação, TPM, duração do ciclo, data de aniversário e dados de controle de natalidade.".

"O uso de lembretes de aplicativos é de grande importância para os esquecimentos do dia-a-dia. Lembretes diários, por exemplo, para o uso de anticoncepcional são muito úteis. Agora que os dados iniciais de cadastro foram realizados, você deve ativar alguns lembretes. Alguns exemplos de lembretes que estão disponíveis no aplicativo Clue são: "Dia da ovulação", "Antes da janela de fertilidade”, "A pílula”, etc. Ative até 3 tipos diferentes de lembretes.".

"Você está se saindo bem, já está com seus dados cadastrados e alguns lembretes ativos. Para finalizar você deve selecionar tipos de monitoramento para lhe ajudar no seu controle. Com isso, selecione três tipos de monitoramentos e preencha as informações necessárias. Exemplos de monitoramento disponiveis: "Sono", "Emoções", "Dor", "Atividades", etc. Um novo monitoramento pode ser cadastrado por você, caso o que desejar não estiver listado no aplicativo.".

Para deixar os usuários mais à vontade optou-se por realizar o teste com cada participante de acordo com a plataforma em que ele já estava acostumado a usar. Portanto dos oito participantes, sete deles realizaram o experimento na plataforma Android e apenas um em iOS.

\footnotetext{
${ }^{5} \mathrm{http}: / / \mathrm{az}-\mathrm{screen}-$ recorder.en.uptodown.com/android
} 


\begin{tabular}{l|l|l|l|l|l} 
& Idade & $\begin{array}{l}\text { Uso de aplicativos para } \\
\text { auxiliar em atividades } \\
\text { diárias }\end{array}$ & $\begin{array}{l}\text { Profundidade do } \\
\text { conhecimento na } \\
\text { utilização de } \\
\text { aplicativos mobile }\end{array}$ & $\begin{array}{l}\text { Utilização de } \\
\text { algum aplicativo } \\
\text { para controle do } \\
\text { seu ciclo menstrual }\end{array}$ & $\begin{array}{l}\text { Conhecimento } \\
\text { sobre o aplicativo } \\
\text { em uso (Clue) }\end{array}$ \\
\hline Participante 1 & 26 & Sim, Uber. & Intermediário & Não & Sim \\
\hline Participante 2 & 54 & Não. & Intermediário & Não & Não \\
\hline Participante 3 & 26 & $\begin{array}{l}\text { Não, uso aplicativos } \\
\text { como Uber, Facebook } \\
\text { e Whatsapp. }\end{array}$ & Intermediário & Não & Não \\
\hline Participante 4 & 26 & Keynote e Drive. & Avançado & Sim & Não \\
\hline Participante 5 & 19 & $\begin{array}{l}\text { Facebook e } \\
\text { Whatsapp. }\end{array}$ & Básico & Sim & Não \\
\hline Participante 6 & 28 & Clue e Santander. & Intermediário & Sim & Sim \\
\hline Participante 7 & 24 & $\begin{array}{l}\text { Sim, Hora da pílula e } \\
\text { Meu remédio. }\end{array}$ & Intermediário & $\begin{array}{l}\text { Sim, Hora da } \\
\text { pílula e Meu } \\
\text { calendário. }\end{array}$ & Não \\
\hline Participante 8 & 31 & $\begin{array}{l}\text { Sim, Google agenda, } \\
\text { CROSSX para o } \\
\text { crossfit e Gmail. }\end{array}$ & Avançado & Não & Não \\
\hline
\end{tabular}

Tabela 6. Perfil dos participantes.

\section{Resultado da Etiquetagem}

Após a aplicação dos questionários e da gravação das telas dos participantes durante a interação com o aplicativo, passou-se para a etapa de etiquetagem e interpretação. Das 13 etiquetas sugeridas pelo MAC, 9 foram identificadas nesta avaliação, conforme gráfico exibido na Figura 7.

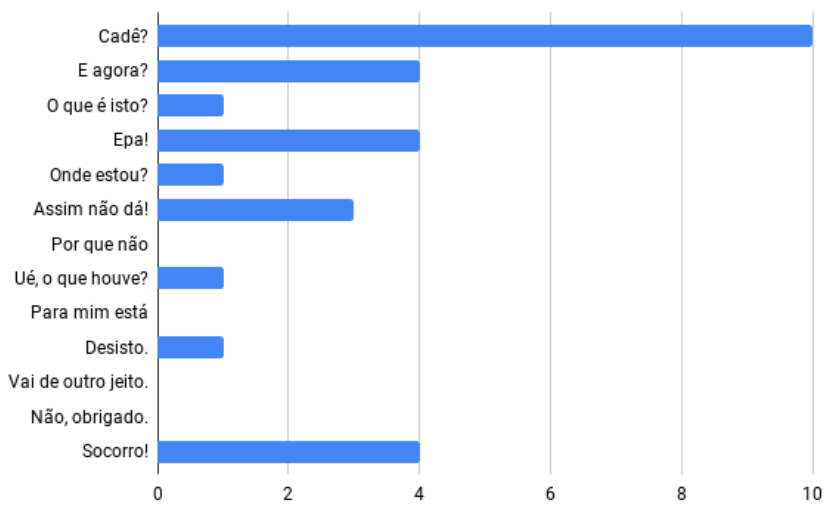

Figura 7. Quantidade de etiquetas identificadas na aplicação do MAC

A maior ocorrência de rupturas de comunicação foi no processo inicial da Tarefa I, quando o participante não precisava criar uma conta no aplicativo para começar a informar seus dados básicos (passo 1). O aplicativo apresenta a opção "Pular criação de conta" no canto superior direito da tela inicial. É importante relatar que das oito interações dos participantes, seis receberam etiquetas neste processo inicial. Para três participantes, a etiqueta
"Socorro!" foi atribuída na interação e para outros dois, a etiqueta "Cadê?". Outro participante recebeu as duas etiquetas, sendo primeiro a etiqueta "Socorro" e logo em seguida a etiqueta "Cadê". Todas essas etiquetas foram atribuídas no momento de pular a criação de conta no aplicativo.

Os participantes demonstraram dificuldades com esta etapa de pular a criação de conta por considerarem o processo confuso. A etiqueta "Socorro!" foi atribuída na mesma parte da interação para quatro dos participantes em função de eles não conseguirem realizar a tarefa através da exploração da interface. Os quatro participantes pediram explicações aos avaliadores para conseguir realizar a etapa de pular conta e seguir com a tarefa. Já a etiqueta "Cadê?" foi atribuída a mesma interação de dois participantes. Eles sabiam a operação que deveriam executar, mas não encontraram de imediato na interface. Identificou-se esta etiqueta pois os usuários inspecionaram diversos elementos de interface como se estivessem procurando a operação que deveria ser executada.

Apenas na interação de um dos participantes foi atribuído a etiqueta "Assim não dá!", três vezes. Esta etiqueta foi atribuída no processo de cadastro dos dados iniciais (passo 5, 6 e 7). O participante comentou que passar por várias telas explicativas era totalmente desnecessário. Além disso, percebeu que a passagem por elas é obrigatória.

Ainda na primeira tarefa, a etiqueta "Ué, o que houve?" e "Desisto." foram atribuídas durante a interação de dois participantes na mesma etapa da tarefa, no momento de 
informar a data de nascimento (passo 8). "Ué, o que houve?" foi etiquetada pois o participante repetiu a operação e comentou que não sabia se a data informada tinha sido salva ou não. Já o "Desisto." foi atribuído pois o participante desistiu de informar sua data de nascimento, porém continuou executando os passos seguintes.

A etiqueta "E agora?" foi identificada durante a finalização da Tarefa 1. A etiqueta foi identificada pois mais de um participante ficou vagando entre os menus e não conseguiu identificar que a tarefa havia sido finalizada.

O restante das etiquetas "Cadê" foi atribuído na segunda tarefa, quando a maioria dos participantes ficou procurando a opção de lembretes no aplicativo. Neste processo as várias rupturas etiquetadas como "Cadê?" foram identificadas porque os participantes não conseguiam encontrar, de imediato, a funcionalidade que desejavam. Os participantes executaram caminhos inapropriados, os quais conseguiram de imediato identificar como errados e logo retornaram para o ponto de partida, caracterizando a ruptura da etiqueta "Epa!".

A alta frequência do "Cadê?" indica que escolhas inadequadas de organização ou expressão dos signos de interface podem ter sido feitas. Todos os participantes em fases alternadas das Tarefa I e II tiveram rupturas de comunicação desta natureza. Alguns usuários relataram, durante o teste, que compreendiam o que precisava ser feito, porém não conseguiam encontrar de imediato na interface.

Percebeu-se, por meio de comentários feitos pelos participantes durante a interação com o aplicativo, que a navegação entre os menus é pouco intuitiva, o que confirma a grande quantidade da etiqueta "Cadê?", e a forma de exibição dos dados é um pouco confusa.

\section{Elaboração do Perfil Semiótico}

Seguindo o MAC, após a interpretação das etiquetas, o avaliador deve elaborar o Perfil Semiótico do sistema avaliado. Nesta etapa, o objetivo é identificar e explicar os problemas de comunicabilidade encontrados. O Perfil Semiótico é elaborado através da reconstrução da metamensagem do designer tal como ela foi recebida pelo usuário [6].

Neste estudo foi tomado como estratégia seguir o modelo de perguntas sugerido por Souza e Leitão [7] para nos guiar nessa elaboração:

Para deixá-los mais à vontade optou-se por realizar o teste com cada participante de acordo com a plataforma em que ele já estava acostumado a usar. Portanto dos oito participantes, sete deles realizaram o experimento na plataforma Android e apenas um em iOS. Em meu entendimento, os usuários do Clue são pessoas adultas do sexo feminino que já possuem experiência com o uso de smartphones e consequentemente já utilizaram algum tipo de aplicativo.
1. O que eu aprendi sobre as necessidades e desejos destes usuários?

Os usuários desejam conseguir controlar melhor seu ciclo menstrual e informações sobre seu corpo. Eles desejam registrar dados sobre si para uma análise posterior, além disso desejam que lembretes sejam disparados em seu smartphone para evitar possíveis esquecimentos.

2. No meu entendimento, quais são as preferências destes usuários com respeito a seus desejos e necessidades, e por quê?

Os usuários preferem que o cadastro seja simples, com poucos campos e rápido de concluir. Também preferem realizar as configurações de notificações de seus lembretes e monitoramentos sem a necessidade de navegação entre vários menus. Eles preferem ver históricos de seu ciclo menstrual e ter um monitoramento sobre informações pessoais de seu corpo.

3. Portanto, qual sistema eu desenhei para estes usuários, e como eles podem ou devem usá-lo?

Desenhei um aplicativo que auxilia as mulheres no controle de seu ciclo menstrual, com o qual é possível registrar diversas informações sobre seu corpo. É possível inserir informações básicas para começar a usar o aplicativo, com a possibilidade de criação de conta ou não. $\mathrm{O}$ aplicativo permite que lembretes de diversos tipos sejam configurados para notificação ao usuário, além disso, é possível ter um histórico de ciclos menstruais conforme o preenchimento dos dados.

\section{Qual é a visão do avaliador?}

O Clue foi desenvolvido pensando na mulher, para registrar informações sobre seu ciclo menstrual e ajudar a monitorar dados sobre seu corpo. Além dos monitoramentos, o Clue permite que lembretes sejam ativados conforme a necessidade do usuário. A configuração de lembretes é importante, pois permite que o usuário configure da maneira que ele necessita e também permite lembrar as mulheres de tomar a pílula todos os dias no mesmo horário. Após a realização do teste e a aplicação dos questionários percebeu-se a necessidade de utilizar telas mais simples para as opções do aplicativo, em função das várias etiquetas atribuídas as interações e também pelos comentários dos participantes durante a realização do teste.

\section{Questionário Aplicado Após a Realização do MAC}

Após a observação dos usuários, com uso do MAC, os participantes foram convidados a responder a um pequeno questionário, consistindo de quatro questões.

A primeira questão tratava das dificuldades encontradas no aplicativo para conseguir atingir os objetivos das tarefas. Apenas um dos participantes respondeu que conseguiu realizar todas as tarefas sem dificuldades, já os outros confirmaram dificuldades durante a interação.

Em relação a utilidade do aplicativo no dia-a-dia, na segunda questão, os participantes confirmaram que sim, o 
uso do Clue é bastante útil no dia-a-dia das mulheres, porém, apenas três dos oito participantes responderam que pretendem seguir utilizando o aplicativo, na questão três. Por fim, na última questão, foi possível concluir que de forma geral os participantes se mostraram satisfeitos com o uso do aplicativo. Nesta questão, foi questionado sobre os pontos fortes e os pontos fracos identificados durante a interação. Em relação aos pontos fortes, os principais comentários dos participantes foram: "O Clue é autoexplicativo...", "Ele tem lembretes, e o que me chama bastante atenção é sobre o período de ovulação, sempre bom saber. ", "Possui diferentes tipos de monitoramento.", "Desenhos de cada monitoramento, facilitando a compreensão; colorido.", "Fácil de usar.". Já como pontos fracos, os participantes descreveram: "Pouco intuitivo", "...me induziu a logar; muitos dados para serem preenchidos para um cadastro sem muita utilização", "...para salvar lembretes e opções de monitoramento eu demorei para achar o lugar. Textos grandes depois de cada etapa. Me incomodou.". Alguns participantes responderam que não encontraram pontos fracos durante a interação.

\section{DISCUSSÃO}

Conforme de Souza [6], além de realizar a classificação das etiquetas de acordo com os problemas descobertos durante o processo de interação no MAC, pode-se realizar também um alinhamento com outros métodos. Este alinhamento, segundo a autora, pode consideravelmente enriquecer a análise e interpretação do avaliador. No caso de ambos métodos aplicados neste trabalho, a autora ainda descreve que, os resultados obtidos do Processo Cognitivo muitas vezes podem ser complementados pelos resultados de uma Avaliação de Comunicabilidade.

Por meio do MAC, foi possível verificar que muitos dos apontamentos feitos pelos avaliadores no MPC se confirmaram. Os participantes tiveram dificuldades nas tarefas realizadas na Avaliação de Comunicabilidade nas mesmas situações que haviam sido apontadas como críticas durante o Percurso Cognitivo.

Os avaliadores, na primeira tarefa, apontaram que a maior dificuldade que os usuários enfrentariam seria passar pelo primeiro passo desta tarefa, acessar o aplicativo e preencher seus dados sem a necessidade de criação de conta. Este apontamento se confirmou após a análise dos dados do MAC. Já na segunda tarefa, os avaliadores apontaram que a dificuldade dos usuários seria em encontrar a opção de lembretes no aplicativo. Por fim, na terceira tarefa, os avaliadores disseram que a mesma seria facilmente realizada pelo fato de os usuários já terem passado pela segunda tarefa. Os apontamentos das duas últimas tarefas também foram confirmados após a realização do MAC. A última tarefa foi realizada com mais facilidade pelos usuários por já terem executado a segunda tarefa e, desta forma, já estarem mais familiarizados com os menus do aplicativo.
No questionário aplicado após o teste, para obter dados sobre o que os participantes acharam do uso do aplicativo, todos concordaram que o mesmo pode ser útil no seu dia-adia, além disso, três dos oito entrevistados afirmam que pretendem começar a utilizar o Clue. Quanto a pontos fracos, os participantes responderam que, principalmente, a navegação entre os menus deve melhorar. No entanto, de maneira geral, todos os participantes gostaram da utilização do aplicativo.

Como limitação deste trabalho, como os testes foram realizados em smartphones (o Clue não possui uma versão desktop), no momento de analisar as gravações de tela, víamos apenas a tela parada, não conseguindo identificar bem todos os momentos em que os usuários podem ter se perdido, mesmo configurando o aplicativo de gravação para exibir os toques em tela (o que é diferente em sistemas desktop, quando conseguimos claramente ver o deslocamento do mouse, por exemplo). Desta forma, algumas informações que poderiam ajudar a uma melhor etiquetagem, podem ter sido perdidas. Fica, como lição aprendida, a necessidade de combinação de uma câmera apontando para as mãos dos usuários, o que possibilitaria obtenção de mais informações, tornando a coleta de dados ainda mais rica.

\section{CONCLUSÃO}

Neste trabalho foi apresentada a aplicação de dois métodos de avaliação de IHC em um aplicativo de apoio às mulheres. O MPC e o MAC foram executados no aplicativo Clue com o propósito de avaliar o fator de usabilidade referente a facilidade de aprendizagem e analisar possíveis rupturas de comunicação referentes à comunicabilidade.

Aplicamos um método de inspeção (MPC) e outro de observação (MAC) a fim de - com a combinação de ambos - se tentar obter resultados mais aprofundados. Como o MPC não envolve de fato os usuários na aplicação do método e o avaliador é quem realiza a análise, alguns problemas podem não ser encontrados, assim como outros pontos podem ser considerados pelo avaliador e não trazerem dificuldades para os usuários. Portanto, segundo Barbosa e Silva [2] devemos, sempre que possível, buscar dados de diferentes métodos para fazer uma análise mais robusta do sistema em questão.

A combinação dos métodos aplicados nos proporcionou uma complementação e confirmação dos resultados. Todos os apontamentos feitos pelos avaliadores na realização das três tarefas aplicadas no MPC foram comprovados após a análise dos resultados do MAC.

Com base nos resultados obtidos, concluímos que o aplicativo Clue possui melhorias que podem ser trabalhadas, visando o maior conforto do usuário final. Algumas dessas melhorias seriam na disposição das suas funcionalidades e na necessidade de telas mais simples.

Recomenda-se como um trabalho futuro uma avaliação mais profunda da utilização do aplicativo pois existem 
funcionalidades que ainda podem ser exploradas. $\mathrm{Na}$ experiência relatada focamos na utilização inicial do aplicativo e nas configurações principais. Seria interessante observar o uso da aplicação por um determinado período de tempo, aprofundando o uso de todas as funcionalidades, a fim de avaliar quais delas realmente são úteis e necessárias e quais estão atrapalhando e onerando o tempo do usuário.

Por fim, os métodos escolhidos nos pareceram adequados, pois, através deles, foi possível um aprofundamento nos resultados obtidos. Ambos os métodos geraram complementaridade, possibilitando, assim, uma melhor análise e confirmação dos problemas encontrados.

\section{AGRADECIMENTOS}

O presente trabalho foi realizado com apoio da Coordenação de Aperfeiçoamento de Pessoal Nível Superior - Brasil (CAPES) - Código de Financiamento 001. Os autores gostariam de agradecer aos participantes voluntários que gentilmente aceitaram fazer parte das avaliações conduzidas neste trabalho.

\section{REFERÊNCIAS}

1. Rosiney R. Almeida e Carlos A. F. de Araújo Jr. 2013. O Uso de dispositivos móveis no contexto educativo: Analise de teses e dissertações nacionais. Revista Tempos e Espaços em Educação. 6, 11 (Junho/Dezembro 2013). http://dx.doi.org/10.20952/revtee.v0i0.2538

2. Simone D. J. Barbosa e Bruno S. da Silva. 2010. Interação Humano-Computador. Elsevier.

3. Carolina C. Bilotti, Larissa D. Nepomuceno, Gabriela M. Altizani, Regiane da S. Macuch, Tiago F. R.

Lucena, Flavio Bortolozzi e Marcelo P. Bernuci. 2017. m-Health no controle do câncer de colo do útero: Prérequisitos para o desenvolvimento de um aplicativo para smartphones. Revista Eletrônica de Comunicação, Informação e Inovação em Saúde. 11, 2 (Junho 2017). http://www.reciis.icict.fiocruz.br/index.php/reciis/articl e/view/1217

4. Raquel O. Prates e Simone D. J. Barbosa. 2007. Introdução à Teoria e Prática da Interação Humano Computador fundamentada na Engenharia Semiótica. Jornadas de Atualização em Informática. 263-326.

5. Yvonne Rogers, Helen Sharp e Jennifer Preece. 2013. Interaction Design: Beyond Human-Computer Interaction, $3^{\text {th }}$, Bookman.

6. Clarisse S. de Souza. 2005. The Semiotic Engineering of Human-Computer Interaction. The MIT Press.

7. Clarisse S. de Souza e Carla F. Leitão. 2009. Semiotic Engineering Methods for Scientific Research in HCI. Morgan \& Claypool Publishers.
8. Chris M. dos S. Tibes, Jéssica D. Dias e Silvia H. ZemMascarenhas. 2014. Aplicativos móveis desenvolvidos para a área da saúde no Brasil: Revisão integrativa da literatura. Revista Mineira de Enfermagem, REME. 18.2 (2014). http://www.dx.doi.org/ 10.5935/14152762.20140035 